\title{
A CRISE DA MOBILIDADE URBANA EM SÃO PAULO
}

\author{
Roberto Salvador Scaringella \\ Engenheiro Civil e Jornalista, Diretor Superintendente do Instituto Nacional de Segurança no Trânsito
}

\begin{abstract}
Resumo: A crise da mobilidade urbana requer a orquestração e a continuidade de uma série de iniciativas que integram os diversos agentes públicos e privados. São traçadas diretrizes que envolvem a combinação das políticas de uso do solo, transporte e trânsito que devem compor a proposta de um modelo sistêmico em uma abordagem profunda que inclua as questões de oferta de infra-estrutura, distribuição nacional de viagens e monitoramento eletrônico do trânsito. E aí a cultura preventiva deve prevalecer em relação à corretiva. As questões de fluidez devem ter importância secundária em relação às de segurança no trânsito. Esta se resume na identificação e no gerenciamento de riscos envolvendo o fator humano, o meio ambiente, a via pública e o veículo.

Palavras-chave: mobilidade urbana; transporte; trânsito e política pública.
\end{abstract}

$\mathrm{O}$ melhor entendimento da crise de mobilidade urbana paulistana passa por uma análise mais detalhada das diversas relações entre: o uso e a ocupação do solo urbano, os sistemas de transporte e a infraestrutura viária e a interação entre fator humano, veículo, via pública e meio ambiente.

A maior cidade brasileira tem $25 \%$ da frota nacional, o que hoje representa perto de cinco milhões de veículos. Praticamente temos um carro para cada dois habitantes. A pesquisa Origem-Destino, realizada a cada dez anos desde 1967, abrangendo a área mais fortemente urbanizada da Região Metropolitana de São Paulo - que registra perto de seis milhões de veículos -, identificou em sua última versão 30 milhões de deslocamentos diários, sendo 10 milhões em transporte coletivo, 10 milhões em transporte individual e os restantes 10 milhões a pé.

Nos últimos 40 anos tem surgido sempre o questionamento sobre o possível futuro colapso ou travamento total do trânsito. A hipótese de caos generalizado baseia-se em premissa falsa. Seria necessário que a cidade se verticalizasse indefinidamente ou que a taxa de motorização chegasse a níveis estratosféricos, o que nunca irá ocorrer. Entretanto, o que se verifica é o aumento do grau e da extensão da área de deterioração do trânsito na cidade, que acaba contribuindo para a degradação urbana.

Num período de cinco anos (entre 1992 e 1997), a média de quilômetros de congestionamento medidos pela CET no sistema viário principal da cidade passou de $40 \mathrm{~km}$, na hora de pico da tarde, para $120 \mathrm{~km}$. Hoje há congestionamentos significativos em corredores da mais longínqua periferia e em todos os quadrantes. O grau de "viscosidade" urbana aumenta, e a crise de mobilidade se agrava. Os deslocamentos ficam mais lentos, e as áreas congestionadas crescem.

Outro aspecto importante a ser considerado é a existência de duas realidades urbanas bem distintas. Como se fossem duas cidades, temos a São Paulo oficial e a clandestina, irregular, completamente fora da lei e de controle.

As ocupações irregulares - favelas de alvenaria - surgem em velocidade e extensão assustadoras, gerando mobilidade clandestina sem planejamento e sem controle. Aliás, o planejamento urbano é um processo praticamente inexistente. $\mathrm{O}$ que se propõe é sempre atrasado e vai a reboque da realidade incontrolada que se implanta apesar do e ao arrepio da lei.

São Paulo tem 14 mil km de vias, sendo 11,7 mil pavimentados e 2,3 mil de vias de terra. O sistema viário principal, onde a maior parte dos deslocamentos ocorrem, pode ser considerado com 2,5 mil km de extensão.

Uma reflexão, ainda que breve e superficial, já mostra, comparando-se alguns parâmetros, que a solução ou mesmo a melhor abordagem da questão da mobilidade urbana não está em atitudes tópicas, empreendimentos pontuais ou ações episódicas. 
É preciso sair da escala do semáforo, do viaduto, do talão de multa ou da placa de sinalização. A extensão e a gravidade do problema do trânsito paulistano requerem uma abordagem sistêmica, uma intervenção profunda com visão de longo prazo. É um desafio tecnológico, político e administrativo que exige um tratamento mais holístico e menos setorizado e um amplo debate com todos os segmentos representativos.

A raiz da crise passa pela disfunção que representa $o$ divórcio entre as políticas de uso do solo, transporte e trânsito. Mesmo que não estejam escritas ou explícitas, elas acabam sendo a sucessão de ações e omissões que a máquina pública permite. Um plano diretor contendo uma política de uso e ocupação do solo pode ajudar muito na racionalização das necessidades de deslocamentos. Sabe-se até pela simples observação visual que a habitação cresce em direção do extremo leste da cidade e o trabalho avança no quadrante sudoeste. $\mathrm{O}$ resultado? Mais viagens, maiores distâncias percorridas e, portanto, mais congestionamentos.

A verticalização da "cidade legal" tem ignorado o impacto no déficit de áreas de estacionamento e, como conseqüência, em São Paulo é praticada uma das tarifas mais altas do planeta.

A administração municipal deve abrir e conduzir o debate a fim de se encontrar esse modelo sistêmico para enfrentar o problema da mobilidade urbana. O esquema clássico de dimensionamento de meios de transportes e de infra-estrutura viária, em função das projeções do crescimento do número de viagens, não mais se aplica, pois levaria a uma inviabilidade.

O novo acordo social deve transcender uma visão setorial e envolve a questão comportamental do público usuário e de metodologias e recursos tecnológicos ainda pouco utilizados no Brasil. Na sua essência, o modelo a ser proposto, debatido, aprovado e implementado deve conter como diretriz básica tecnologia atualizada, variável política bem conduzida e uma saudável ação administrativa.

A complexidade do problema, os fatores limitantes, o obrigatório envolvimento e o comprometimento da comunidade é que darão respaldo a sua intervenção ampla e profunda. Não será um plano ou modelo que sairá de uma única prancheta, por melhor que seja o projetista.

O referido modelo deve ter, em primeiro lugar, dados e informações consistentes. Só se conseguirá transformar adequadamente qualquer realidade se houver um adequado conhecimento da mesma. As pesquisas decenais de origem-destino a partir de 1967 serão muito úteis, mas insuficientes.
Juntar urbanistas, técnicos de transporte urbano e os de trânsito não constituirá tarefa muito fácil, porém será essencial para acabar com o já tradicional divórcio das três "falanges".

Muito se pode racionalizar, sintonizando as três políticas. Além de dados e da aproximação do uso de solo-transporte-trânsito, é preciso desenvolver ações de aumento da oferta de infra-estrutura, racionalização da demanda de viagens e monitoramento eletrônico do trânsito.

O crescimento da oferta de capacidade do sistema viário e do transporte coletivo de grande capacidade, que sempre envolve capital intensivo, tem sido uma solução absolutizada pelo poder público e pelas comunidades científica e tecnológica, sem deixar de citar a iniciativa privada. É a escola do "hardware urbano". O erro não está em valorizar a grande obra, e sim absolutizá-la, como se ela fosse a única e completa solução. Essa é uma visão limitada da realidade e característica de países menos desenvolvidos.

A supervalorização da "cirurgia" urbana não é corrente nos países de Primeiro Mundo, onde há o primado do "software urbano" em relação ao "hardware urbano". Racionalizar o uso da infra-estrutura já existente tem prioridade em relação a novas soluções de capital intensivo.

Foi um marco, na década de 60 , a contratação de consultoria estrangeira pela administração municipal. Isso ocorreu durante as primeiras pesquisas, e o estudo da viabilidade técnica econômica e financeira do metrô de São Paulo foi importante, principalmente pelas ferramentas de análise e projeção de viagens utilizadas, que proporcionaram um entendimento adequado às questões de mobilidade. Concluído na época em que se acreditava no "milagre brasileiro", esse estudo animou técnicos e administradores públicos a propor um sistema estrutural de vias expressas que acabaram se transformando em vias apenas "impressas" em coloridos relatórios técnicos.

Buscava-se na época o que se acreditava um modelo técnico-clássico para o futuro final do milênio, ou seja: malha de $400 \mathrm{~km}$ de vias expressas, rede metroviária de quase $200 \mathrm{~km}$ e modernização da ferrovia suburbana, que, na rede metropolitana, soma $270 \mathrm{~km}$.

Nem a crise do petróleo do início da década de 70 foi suficiente para mostrar a limitação do modelo. De lá para cá as dificuldades só aumentaram.

Os defensores do modelo clássico não conseguiram ver que em primeiro lugar não existiriam recursos financeiros e, mesmo que existissem, não haveria tempo (a frota dobra a cada dez anos). Caso houvesse tempo e dinheiro, não existiria espaço para ampliar o complexo viário se- 
gundo as projeções. Tudo isso frustrou muita gente que insistiu na sangria dos cofres públicos para privilegiar obras em relação aos serviços, resultando em uma cidade ainda desequilibrada sob vários aspectos.

Há de se ressaltar que, numa cidade com dez milhões de habitantes e cinco milhões de veículos, não há obra viária ociosa, qualquer que seja. Entretanto, é preciso uma visão menos setorial e mais social do problema.

Hoje fala-se muito do rodoanel, que, em $35 \mathrm{~km}$ de obra, vai sorver perto de 800 milhões de reais, e a Prefeitura de São Paulo diz que não vai colocar os prometidos $200 \mathrm{mi}$ lhões acordados pela antiga administração.

A pergunta que se faz é: quando a obra completa, que deverá custar perto de seis bilhões de reais, ficará pronta? Nessa data qual será a frota circulante? O recurso virá de onde? Que outros projetos, metas e serviços serão preteridos?

Os técnicos têm afirmado que só com a cobrança do pedágio o rodoanel não se viabiliza. O sistema metroviário, de grande eficiência, hoje soma $50 \mathrm{~km}$ de rede e deveria ser no mínimo dez vezes maior pela escala da cidade. Essa perspectiva já indica que perdemos o bonde da história pelo prazo e pelos custos inviáveis. Infelizmente. O sistema de metrô está saturado e já pede a desintegração entre ônibus e metrô (vide Estação Tatuapé), que foi grande meta há 25 anos, quando a primeira integração ocorreu.

Tem enorme importância a modernização do sistema ferroviário de passagens de subúrbio. $\mathrm{O}$ uso de uma tecnologia de nível metroviário garantiria enorme benefício a toda a região metropolitana. Apesar dos esforços para isso, é preciso buscar solução na escala de $270 \mathrm{~km}$ e não menos.

A questão do estacionamento tem sido pouco considerada no debate das soluções de mobilidade. Historicamente nos últimos 30 anos pouca importância foi dada ao tema. Tudo se passou como se o estacionamento não fosse parte essencial do trânsito urbano.

\section{RACIONALIZAÇÃO DA DEMANDA DE VIAGENS}

A já mencionada concentração urbana, a distribuição irracional de horários de atividades - gerando deslocamentos pendulares simultâneos -, a precariedade do transporte coletivo e o sistema viário insuficiente são um convite ao desenvolvimento de soluções de "software urbano", procurando racionalizar os deslocamentos e as atividades dentro da infra-estrutura já existente.
A maioria dos deslocamentos inevitavelmente deve ocorrer em determinado momento nas condições permanentes, entretanto pouca gente conjectura se há ou não alternativa.

A partir da informação obtida para enfrentar um deslocamento com o trânsito muito lento, deve-se, quando possível:

- Alterar o horário, o percurso, o modo de transporte e/ ou o destino da viagem.

- Não executar a viagem.

- Enfrentar com consciência a dificuldade e ir em frente.

De toda forma é melhor se ter várias opções do que apenas uma. Uma questão da qual muito se fala - mas pouco se faz - é a implantação concreta de medidas que diminuam o tamanho e o número de deslocamentos, como, por exemplo, uma legislação que beneficie assentamentos de áreas-dormitório próximas a postos de trabalho. Mesmo que em escala relativamente pequena, o impacto no trânsito seria significativo.

O escalonamento dos horários de trabalho ou das diferentes atividades até certo ponto já existe, porém sua ampliação costuma atrapalhar a vida de quem tem mais de uma atividade (geralmente escola e trabalho).

Há poucos dados e estudos consistentes a esse respeito. Infelizmente o debate tem sido muito baseado em "achismos". Note-se, entretanto, que as facilidades da informática, do geoprocessamento, dos bancos de dados e das simulações eletrônicas poderiam iluminar muito essa discussão. Melhores soluções apareceriam.

O transporte de cargas com caminhões grandes, médios e pequenos ajuda a complicar a situação. Não faltaram tentativas nos últimos anos em usar horas ociosas de pouco movimento para se fazer o transporte e a operação de carga e descarga. O transportador gosta da idéia, a população que enfrenta o trânsito aplaude, entretanto os responsáveis pelos pontos de recebimento não concordam em ter em seu estabelecimento equipes de pessoal e segurança para receber a carga em horários não-comerciais. $\mathrm{O}$ acordo nunca foi possível.

É de se notar que propostas alternativas de uma distribuição mais inteligente de viagens ou deslocamentos são uma forma de melhorar o trânsito sem grandes investimentos, porém é necessária muita vontade política para convencer as pessoas, físicas ou jurídicas, inclusive políticos, a mudarem de comportamento.

Muitos preferem a liberdade de perder tempo e dinheiro no congestionamento a alterar hábitos. Não se pode dis- 
cutir medidas de racionalização de deslocamentos sem que se considere o rodízio municipal. Se não é uma solução profunda, inegavelmente hoje diminui o número de quilômetros de congestionamento no centro expandido da cidade.

Se pudéssemos ter uma foto aérea de todo o sistema viário da cidade na hora de pico da tarde, por exemplo, não teríamos certamente toda a frota de veículos circulando ao mesmo tempo, pois isso não é mais possível há décadas. Se cada munícipe motorizado, usando seu direito constitucional de ir e vir, tivesse a idéia de sair na mesma hora com seu veículo, isso seria fisicamente impossível. A cidade já se "afoga" em congestionamentos com $25 \%$ da frota circulando ao mesmo tempo. Portanto, a solução do rodízio guarda dentro de si uma dinâmica que anula com o tempo o benefício pretendido, não somente pela aquisição de um segundo veículo (geralmente mais poluidor), como também a reserva de carros viáveis no rodízio vai sendo mobilizada.

Outra limitação do rodízio, que é uma regulamentação que pretende ser sistêmica, é a fiscalização manual, portanto parcial e precária. Mesmo assim, cada dia perto de três mil condutores são multados por desrespeitar o rodízio.

A prefeitura tem um desafio ainda não suficientemente abordado: como administrar a escassez crescente de espaço para circular. A solução tem de ser tecnicamente viável e socialmente o mais justa possível. Hoje quem não tem veículo próprio e é usuário cativo de ônibus é penalizado pelo congestionamento provocado pelo carro particular. É injusto!

Quando existe uma escassez de um bem público, deve ser administrada a cobrança pelo uso. É o caminho de maior justiça e viabilidade. A cidade adotou esse caminho, quando criou, há mais de 20 anos, a Zona Azul. Faltava espaço para todos estacionarem livremente junto ao meio fio e decidiu-se cobrar pelo uso. É bom lembrar que depois de grande celeuma foi o próprio comércio, que antes reclamava, que passou a solicitar a ampliação do sistema. Isso porque eram os próprios comerciantes que deixavam seus carros estacionados, impedindo o uso de vagas para seus clientes. Foi fácil mostrar que cada vaga passou a ser usada em média por quatro ou cinco carros cada dia. Houve, portanto, aumento de capacidade. Hoje São Paulo tem 29 mil vagas de Zona Azul.

Em qualquer sistema viário saturado a retirada efetiva de $20 \%$ dos veículos que circulam principalmente nos horários críticos representa um efeito de fluidificação do trânsito. Resta discutir como retirá-los. É oportuno lem- brar que, ao contrário de países como o Japão, aqui, mesmo sem provar que se tem onde guardar o veículo, o cidadão pode comprá-lo sem qualquer impedimento. A experiência internacional (como a do México) não recomenda o rodízio "dia par com par" como eficaz o suficiente. Inevitavelmente a cidade deverá debater a solução do trânsito tarifado ou o pedágio urbano.

$\mathrm{O}$ agravamento da dificuldade de circular e o crescimento do número de quilômetros de congestionamento, fazendo aumentar ainda mais a escassez de espaço viário, leva a se considerar o deslocamento em automóvel particular, em vias saturadas e nas horas de pico, um verdadeiro privilégio.

O espaço é insuficiente para atender a toda a demanda. A tarifação das vias saturadas nos horários mais críticos por meio de controle eletrônico - que possibilita a identificação do veículo em movimento - deve garantir a retirada de circulação nas vias tarifadas de $20 \%$ da frota, o que possibilita fluidificar o trânsito.

O sistema não tarifa áreas, e sim vias, o que resulta de fato em melhor distribuição de deslocamento do veículo particular no uso do sistema viário público.

O pedágio urbano é uma tese debatida há muito tempo. Um dos motivos de sua não-utilização era a falta de tecnologia para identificar o veículo em movimento, dificuldade hoje superada no Brasil. A tarifação do trânsito urbano já é aplicada em algumas partes, e a comunidade técnica mundial transformou-a em assunto de grande atualidade. O pagamento direto pelo exercício de privilégio do uso de um bem cuja oferta é escassa permite reinjetar os recursos arrecadados na ampliação do sistema de transporte coletivo de qualidade, o que, por sua vez, facilitará ainda mais a retirada de carros particulares de circulação.

É importante alocar custos de modo mais eqüitativo, associando-o ao uso, em vez de socializá-lo por via tributária. Uma das formas, talvez a melhor, de se associar o pedágio urbano à implantação de projetos definidos como, por exemplo, o metrô, o rodoanel e o monitoramento eletrônico do trânsito - é transferir a tarefa para a iniciativa privada.

O poder concedente não investe, apenas controla, regulamenta e garante a aplicação dos recursos para as finalidades previstas e visíveis ao público usuário.

Tecnicamente o problema já está resolvido; entretanto o ponto crucial encontra-se na decisão política da cobrança do pedágio. Muitas vezes o político quer buscar saídas a partir de ações simpáticas e indolores. Não raramente fixase no poder das grandes obras, vive a frustração da falta 
de recursos para realizá-las e ignora o certo potencial administrativo, técnico e político das medidas operacionais e de racionalizar o uso do espaço e da infra-estrutura existentes.

A resistência em se arbitrar uma tese mais ousada e moderna resultará no agravamento e na degradação da qualidade de vida urbana. Até quantos quilômetros de congestionamento a cidade suporta?

Há seis anos realizamos, juntamente com um grupo de engenheiros, um estudo apresentado em congresso da Anip no qual se simulava a tarifação de $212 \mathrm{~km}$ do sistema viário principal saturado, cobrada por meio de pedágio eletrônico, o que geraria uma receita anual de aproximadamente 700 milhões de reais.

\section{MONITORAMENTO ELETRÔNICO DO TRÂNSITO}

Há muito administrador público que reduz a questão do controle de trânsito a talões de multa, semáforos, placas e alguma "pintura" de solo. Tudo se passa como se o trânsito se auto gerisse.

$\mathrm{O}$ agente ativo do processo seria o condutor, geralmente indisciplinado e culpado de tudo o que de inconveniente acontece na via pública. É preciso lembrar que trânsito não é mais matéria de tratamento intuitivo ou de repressão policial apenas. O problema é complexo e pede tecnologia.

A informática, a engenharia de tráfego, a eletrônica, a tecnologia comportamental e a democratização da informação são ferramentas essenciais e que modernamente compõem o que se chama de trânsito inteligente. A informática está cada vez mais potente, barata e amigável ao usuário. É inadmissível que São Paulo tenha apenas 25\% de semáforos inteligentes. A eletrônica está aí para ser implantada. Painéis de mensagens variáveis e circuito de televisão são essenciais.

O monitoramento eletrônico do trânsito em São Paulo deu os primeiros passos no pioneirismo dos semáforos coordenados e eletronicamente controlados a partir de 1982. O que falta é escala e atualização tecnológica. Afinal, em informática, um equipamento de 20 anos é quase pré-histórico.

O sistema de trânsito não depende apenas do poder público. O desempenho do trânsito depende também da atuação do condutor e do pedestre. Esta por sua vez depende do grau de informação que se disponibiliza ao uso público. A informação pode fazer com que o cidadão aumente o número de alternativas para enfrentar o problema de seu deslocamento, tanto na cidade como na rodovia. A identificação eletrônica do veículo - que deve ser entendido como parte do trânsito inteligente - é fator essencial na solução do pedágio urbano e já constitui realidade em algumas rodovias. O sistema é útil para todo o monitoramento do trânsito e beneficia inclusive a segurança pública.

Durante aprovação do já nem tão novo Código de Trânsito Brasileiro, sancionado em 23/09/1997, houve um retrocesso lamentável, pois o Senado havia aprovado a obrigatoriedade da identificação eletrônica de veículos, cuja tecnologia já é dominada por muitas empresas no Brasil. Foi reprovada quando o projeto de lei voltou à Câmara dos Deputados, usando-se a justificativa incoerente de limitação tecnológica e a existência de hipotético e incorreto risco de monopólio tecnológico.

$\mathrm{O}$ resultado foi o atraso. $\mathrm{O}$ argumento de invasão de privacidade não é válido, pois no sistema bancário informatizado esse assunto tem solução quase trivial, bem como no caso da telefonia. A fiscalização de pagamento do IPVA já seria uma justificativa mais do que suficiente. Mais de $20 \%$ da frota em todos os Estados, inclusive na cidade de São Paulo, não paga e não é fiscalizada, e o Estado e a prefeitura perdem muito dinheiro. O número de carros furtados ou roubados é grande, e o recurso eletrônico seria eficaz no combate a esse tipo de crime.

Na questão do trânsito, ou mesmo nessa questão mais ampla da mobilidade urbana ou interurbana; não existe um único remédio que resolva tudo. É com o somatório e a orquestração inteligente de ações (continuadas) que teremos resultados saudáveis para toda a população.

A cultura brasileira não tem sido generosa com atitudes preventivas. No trânsito não é diferente. Além disso, quando se fala em problemas no trânsito, geralmente reduz-se o tema às questões de fluidez, quando o maior desafio é a segurança, ou seja, buscar reduzir o número e a gravidade dos acidentes.

A metodologia mais eficaz para o desenvolvimento de segurança no trânsito está na prevenção. Em primeiro lugar busca-se saber identificar riscos e, logo a seguir, fazer o gerenciamento dos mesmos riscos envolvendo o fator humano, o meio ambiente, a via pública e o veículo. É importante defender o primado da segurança em detrimento da fluidez a partir da importância que deve ser dada à preservação da vida. 